\title{
An inverse source problem for a two dimensional time fractional diffusion equation with involution
}

\author{
Batirkhan Turmetov ${ }^{1}$ and B. J. Kadirkulov ${ }^{2}$ \\ ${ }^{1}$ Khoja Akhmet Yassawi International Kazakh-Turkish University \\ ${ }^{2}$ Tashkent State Institute of Oriental Studies
}

June 13, 2021

\begin{abstract}
In this paper, we consider a two-dimensional generalization of the parabolic equation. Using the Fourier method, we study the solvability of the inverse problem with the Dirichlet condition and periodic conditions.

\section{Hosted file}

InvPrInvol.pdf available at https://authorea.com/users/62597/articles/525999-an-inversesource-problem-for-a-two-dimensional-time-fractional-diffusion-equation-with-involution
\end{abstract}

